\title{
Verrucous Hemangioma Treated with Electrocautery
}

\author{
Mohammad Fatani ${ }^{a} \quad$ Homaid Al Otaibi ${ }^{b} \quad$ Muath Mohammed \\ Osama Hegazy ${ }^{d}$ \\ ${ }^{a}$ Department of Dermatology, Hera General Hospital, Makkah, Saudi Arabia; \\ ${ }^{b}$ King Faisal Hospital, Makkah, Saudi Arabia; ${ }^{\circ}$ Umm al Qura University, Makkah, \\ Saudi Arabia; ${ }^{\mathrm{d} D e p a r t m e n t}$ of Pathology, Hera General Hospital, Makkah, Saudi Arabia
}

\section{Keywords}

Verrucous hemangioma $\cdot$ Hyperkeratosis · Electrocautery

\begin{abstract}
Verrucous hemangioma is a rare vascular malformation consisting of a proliferation of dilated blood vessels of different sizes that occupy the dermis and hypodermis. The epidermis of the affected area shows a strong proliferative reaction that presents as a warty appearance. Here, we report the case of a 17-year-old male who presented with an asymptomatic warty growth above the lateral malleolus on the right leg, which healed after electrocautery.
\end{abstract}

\section{C) 2016 The Author(s)}

Published by S. Karger AG, Basel

\section{Introduction}

Verrucous hemangioma is a rare, congenital, capillary or cavernous hemangioma presenting as vascular papules, plaques, or nodules and characterized by vascular proliferation and dilation from the dermis to subcutaneous tissue, along with the proliferative reaction of the epidermis [1]. It often unilaterally involves the lower extremities and spreads slowly. As it spreads, disseminated nodules may develop [2]. In general, the condition is observed at birth or in early childhood. In early manifestations, it is bluish-red in color. Secondary infection, a frequent complication, results in reactive papillomatosis and hyperkeratosis; thus, older lesions acquire a verrucous or warty surface [3]. Unlike other angiomatous nevi, it 
does not involute spontaneously. Clinically, the lesions may resemble angiokeratoma, lymphangioma circumscriptum, verrucous epidermal nevus, verrucous cancer, or even malignant melanoma [4].

\section{Clinical Details}

The patient was a 17-year-old man with no known drug allergies who presented with an asymptomatic, verrucous skin lesion on the lower right leg he had had since childhood. Initially described as a progressively enlarged, exuberant, warty, and violet-colored growth, it had an overlying hemorrhagic crust. Upon examination, his vital signs were as follows: blood pressure of $130 / 80 \mathrm{~mm} \mathrm{Hg}$, heart rate of $80 \mathrm{bpm}$, respiration of $20 / \mathrm{min}$, temperature of $37^{\circ} \mathrm{C}$, weight of $101 \mathrm{~kg}$, and height of $172 \mathrm{~cm}$.

Initial dermatologic examination revealed a solitary, well-circumscribed, brownish, hyperkeratotic, and hemorrhagic-crusted nodule that was easy to bleed and measured $3.0 \times 2.5$ $\mathrm{cm}$ on the right leg above the lateral malleolus. Its surface was firm and verrucous; it bled easily and was surrounded by darker pigmentation (fig. 1). The lesion was noncompressible, and the regional lymph nodes were not enlarged. Our initial diagnosis was pyogenic granuloma. The lesion was treated with cryotherapy. Initial follow-up after 10 days revealed mild regression of the lesion. However, the lesion became painful. Clinically, we saw a wellcircumscribed, solitary, pedunculated, and hemorrhagic nodule with a crusted surface oozing from the lateral margin and hyperpigmented surrounding skin. Cryotherapy was repeated.

After 10 more days, at the second follow-up, the lesion had mildly shrunk in size. However, at this point, electrocautery was performed; figure 2 depicts the lesion immediately following the procedure. Histopathological examination showed verrucous epidermal hyperplasia with superficial ulceration and extensive crust formation. This condition is associated with hyperkeratosis and parakeratosis. In the underlying dermis, there is a proliferation of cavern-type vascular spaces filled with red blood cells (fig. 3), which suggested the diagnosis of verrucous hemangioma. The lesion healed in response to electrocautery, with no recurrence after 1 year.

\section{Discussion}

Verrucous hemangioma is a rare, congenital, and localized vascular malformation [3]. It has been reported under various names, including unilateral verrucous hemangioma, hemangioma unilateralis neviforme, nevus vascularis unius lateris, nevus angiokeratoticus, keratotic hemangioma, nevus keratoangiomatosus, and papular angiokeratoma [5]. Imperial et al. [3] introduced the term 'verrucous hemangioma' in 1767, describing a congenital, vascular malformation comprising a capillary or cavernous hemangioma in both the superficial and the deep dermis, as well as in subcutaneous tissue.

This lesion most frequently presents at birth or in early childhood, with the commonest site being the lower extremities. The lesion tends to be unilateral, well defined, bluish-red, discrete, grouped, soft, and compressible; lesions vary in size between $4 \mathrm{~mm}$ and $7 \mathrm{~cm}$ in diameter, and minor satellite lesions are often present [6]. Secondary bleeding and superimposed infection are frequent complications, which often result in reactive papillomatosis and 
hyperkeratosis; thus, older lesions often acquire a warty texture [7]. The lesion can sometimes present in a linear or serpiginous fashion [8].

Diagnosis of verrucous hemangioma is primarily based on histopathological examination, as in our case, although clinical correlation is required to confirm the diagnosis [9]. Histologically, verrucous hemangioma shows with hyperkeratosis, variable epidermal acanthosis, and papillary telangiectasias overlying a deep capillary or cavernous hemangioma [5]. The abnormal proliferating vessels are situated in the dermis and hypodermis. The hemangiomatous component mostly comprises dilated capillaries and wider cavernous, endothelium-lined, blood-filled spaces. Inflammatory cells, fibrosis, and hemosiderin may exist in the upper dermis [2].

A previous study has reported positive expression of Wilms tumor 1 (WT1) and glucose transporter 1 (Glut-1) proteins in cases of verrucous hemangioma [10]. Further study with a larger sample size showed an incomplete lymphatic immunophenotype, as indicated by positive staining for Prox1 and negative staining for WT1 in the majority of instances [11].

Interestingly, coexistence of eccrine angiomatous hamartoma and verrucous hemangioma has been found [12]. Eccrine angiomatous hamartoma has been reported in combination with other vascular tumors in only a few instances, such as verrucous hemangioma or overlying verrucous-hemangioma-like features [13].

The differential diagnosis includes angiokeratoma, Cobb syndrome, angioma serpiginosum, lymphangioma circumscriptum, cutaneous keratotic hemangioma, blue rubber bleb nevus, papillomas, tumors (including melanoma), and verrucae [5, 8]. Dermal and subcutaneous verrucous hemangioma have specific MRI features, making MRI useful in differentiating such verrucous hemangioma from angiokeratoma with similar clinical features [14]. Furthermore, such dermoscopic features may be helpful in diagnosing diseases that differ by the type and area of their associated lesions [15].

Unlike other angiomatous nevi, verrucous hemangiomas do not resolve spontaneously and tend to relapse. Early diagnosis is important to obtain an excellent cosmetic outcome. Verrucous hemangioma should be excised while still small to prevent large and unsightly scars. The treatment of choice for verrucous hemangiomas is wide and deep surgical excision in order to ensure free margins to reduce the chance of possible recurrences, as a superficial therapeutic approach would be unsuccessful because of the deep angiomatous proliferation $[16,17]$. Other options have been tried with limited results, including ultrasound, cryosurgery, and electrocautery, especially for smaller lesions [7, 18, 19]. Recently, treatment with a combination of $\mathrm{CO}_{2}$ and dual pulsed-dye laser-Nd:YAG has in some cases provided a satisfactory response [20].

In our case, the initial clinical diagnosis was pyogenic granuloma, which is why we began treatment with two cycles of cryotherapy. We noted mild regression of the disease and followed with electrocautery. Later, the diagnosis of verrucous hemangioma was based on histopathological examination. Notably, the lesion healed with no recurrence and with acceptable cosmetic outcome.

\section{Conclusion}

We report this case for its rarity of occurrence and its clinical implications for the differential diagnosis of various conditions, including melanoma, as described above. Furthermore, we mention the therapeutic role played by electrocautery, which in our case demonstrated significant resolution. 


\section{Statement of Ethics}

The patient gave written informed consent.

\section{Disclosure Statement}

The authors declare no conflicts of interest.

\section{References}

1 França ER, Gurgel A, Campos T, Souza JA, França K, Azevedo R: Verrucous hemangioma. An Bras Dermatol 2006;81(suppl 3):S290-S292.

2 Bindhuja J, Rajendiran S, Priyathersini N, Balaji Singh K, Leena DJ: Verrucous hemangioma: a rare vascular tumor - a case report. Sri Ramachandra J Med 2013;6:2021.

3 Imperial R, Helwig EB: Verrucous hemangioma. A clinicopathologic study of 21 cases. Arch Dermatol 1967;96:247-253.

4 Yasar A, Ermertcan AT, Bilac C, Bilac DB, Temiz P, Ozturkcan S: Verrucous hemangioma. Indian J Dermatol Venereol Leprol 2009;75:528-530.

5 Calduch L, Ortega C, Navarro V, Martínez E, Molina I, Jordá E: Verrucous hemangioma: report of two cases and review of the literature. Pediatr Dermatol 2000;17:213-217.

6 Lynch PJ, Kosanovich M: Angiokeratoma circumscriptum. Arch Dermatol 1967;96:665-668.

7 Wang G, Li C, Gao T: Verrucous hemangioma. Int J Dermatol 2004;43:745-746.

8 Jain VK, Aggarwal K, Jain S: Linear verrucous hemangioma on the leg. Indian J Dermatol Venereol Leprol 2008;74:656-658.

9 Nag F, Biswas S, Surana T, Ghosh A, Chatterjee G: Disseminated verrucous hemangioma with subcutaneous hemangioma: a rare association. Iran J Dermatol 2013;16:39-41.

10 Trindade F, Torrelo A, Requena L, Tellechea O, Del Pozo J, Sacristán F, Esteve-Martínez A, de Unamuno B, de Miquel VA, Colmenero I: An immunohistochemical study of verrucous hemangioma. J Cutan Pathol 2013;40:472-476.

11 Wang L, Gao T, Wang G: Verrucous hemangioma: a clinicopathological and immunohistochemical analysis of 74 cases. J Cutan Pathol 2014;41:823-830.

12 Cheong SH, Lim JY, Kim SY, Choi YW, Choi HY, Myung KB: A case of eccrine angiomatous hamartoma associated with verrucous hemangioma. Ann Dermatol 2009;21:304-307.

13 Lin Y, Chen C, Yang C, Chang YH: Eccrine angiomatous hamartoma: a retrospective study of 15 cases. Chang Gung Med J 2012;35:167-177.

14 Nagarajan K, Banushree CS: Usefulness of MRI in delineation of dermal and subcutaneous verrucous hemangioma. Indian J Dermatol 2015;60:525.

15 Prabhakar V, Kaliyadan F: A case of verrucous hemangioma and its dermoscopic features. Indian Dermatol Online J 2015;6(suppl 1):S56-S58.

16 Mestre T, Amaro C, Freitas I: Verrucous hemangioma: a diagnosis to consider. BMJ Case Rep 2014;2014:bcr2014204612.

17 Nupur P, Savant SS, Kumar P, Hassan S: Linear verrucous hemangioma. Indian Dermatol Online J 2014;5(suppl 2):S136-S137.

18 Maejima H, Katsuoka K, Sakai N, Uchinuma E: Verrucous hemangioma successfully treated using 13MHz ultrasonography. Eur J Dermatol 2008;18:597.

19 Achar A, Biswas SK, Maity AK, Naskar B: Verrucous hemangioma treated with electrocautery. Indian J Dermatol 2009;54(suppl S1):51-52.

20 Segura Palacios JM, Boixeda P, Rocha J, Alcántara González J, Alonso Castro L, de Daniel Rodríguez C: Laser treatment for verrucous hemangioma. Lasers Med Sci 2012;27:681-684. 


\section{Case Reports in

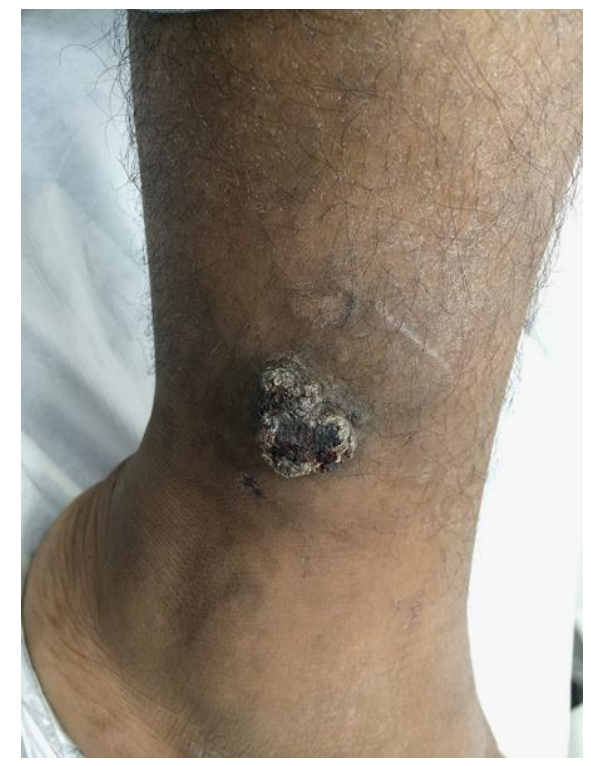

Fig. 1. Hyperkeratotic and hemorrhagic-crusted, verrucous surface nodule on the right leg.

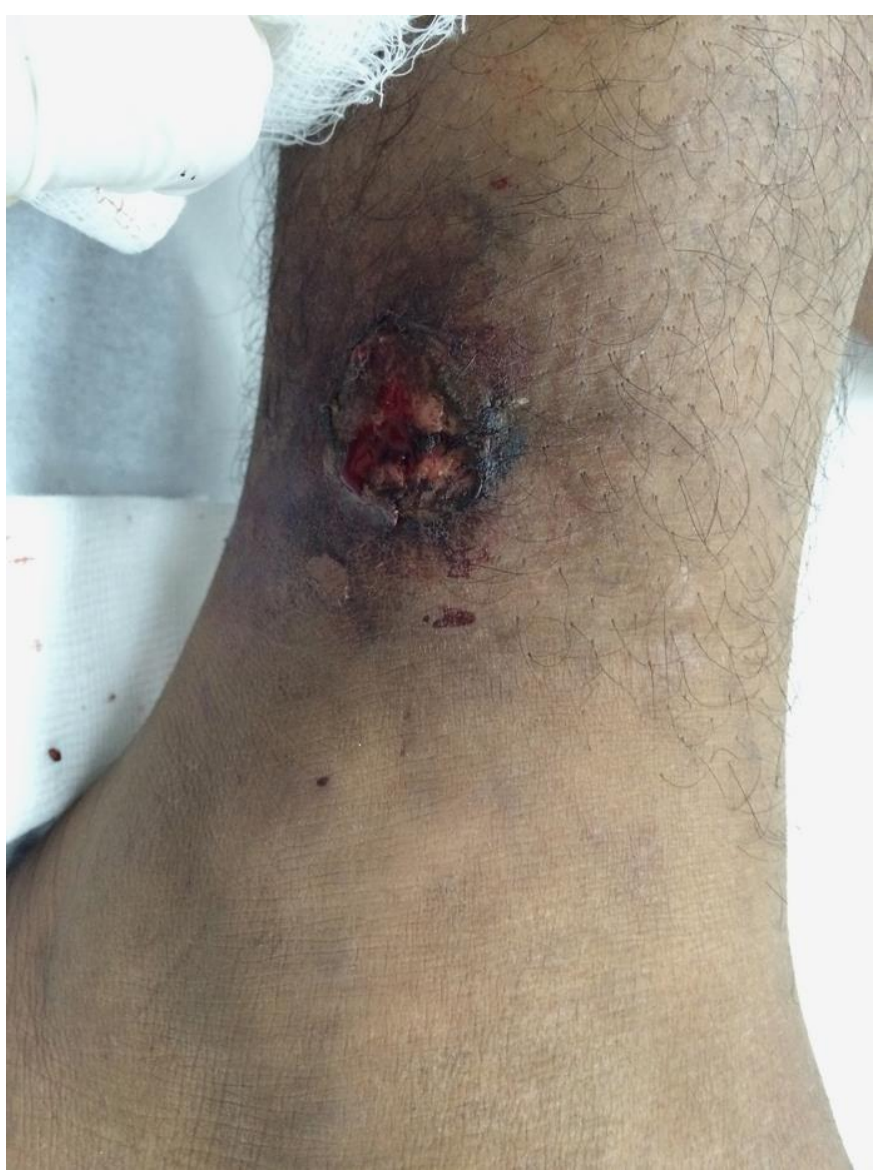

Fig. 2. The lesion immediately following the procedure. 


\section{Case Reports in Dermatology}

Case Rep Dermatol 2016;8:112-117

(C) 2016 The Author(s). Published by S. Karger AG, Basel www.karger.com/cde

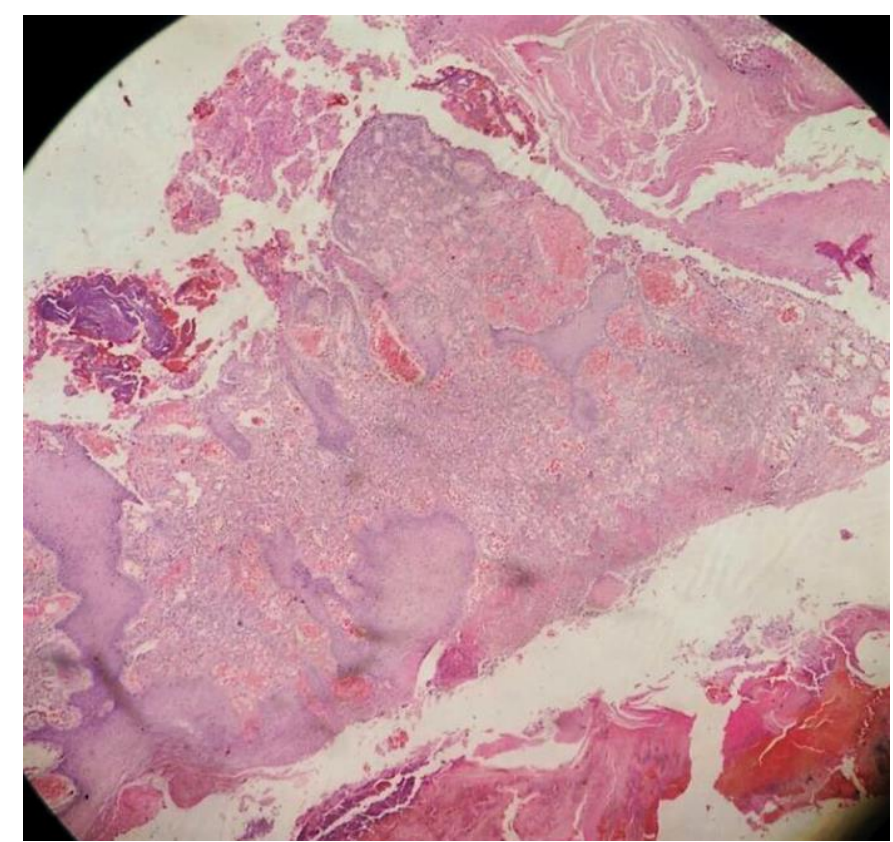

Fig. 3. Proliferation of cavern-type vascular spaces filled with red blood cells. 